\title{
Unified Presentation of Weir-Aeration Data
}

\author{
By Mark Markofsky ${ }^{1}$ and Helmut Kobus, ${ }^{2}$ Members, ASCE
}

INTRODUCTION

Much research has been performed in recent years in an attempt to quantify the increase in dissolved oxygen (reoxygenation) in water splashing into a pool at the base of a free weir. Model studies $(4,8,11,14,16)$ and field measurements $(1,7,5,13,15)$ have provided data over a wide range of heights of fall, flow rates, temperatures, and water quality. Here, as in all problems involving air-water mixtures, the question of correlating the results from small-scale laboratory models to prototype dimensions is of primary importance. In the present note, the data available for two-dimensional free overfall weirs are critically reviewed and presented in nomogram form in an attempt to quantify model scale effects. Primarily two parameters, i.e., a jet Froude number and a jet Reynolds number, determine the degree of reoxygenation in the range of flows normally encountered in the laboratory and in small streams [discharge per unit width $q_{w}<0.2$ $\left.\mathrm{m}^{3} / \mathrm{s} \cdot \mathrm{m}-0.5 \mathrm{~m}^{3} / \mathrm{s} \cdot \mathrm{m}(2.15 \mathrm{cu} \mathrm{ft} / \mathrm{sec}-\mathrm{ft}-5.37 \mathrm{cu} \mathrm{ft} / \mathrm{sec}-\mathrm{ft})\right]$, whereas only the jet Froude number is of importance in large scale installations. This conclusion is restricted to the condition that the plunge pool is "deep," and that the water temperature and water quality parameters remain constant. The effect of variation from these assumptions is also examined.

The process of reoxygenation can be considered in three successive parts: (1) Mechanics of air entrainment; (2) mechanical transport of the air away from the entrainment location; and (3) transfer of oxygen from the air bubbles into solution. The first two steps depend only on the hydrodynamics of the air-water mixture, whereas the third part represents the chemical phase of the process which depends upon the water quality, such as temperature, initial dissolved oxygen content, salinity, and degree of water pollution.

In the following, the analysis will be limited to the mechanics of air entrainment, assuming that the second step (air transport) is not a limiting factor (i.e., deep plunge pools) and that the parameters affecting the gas transfer process remain constant.

Note.-Discussion open until September 1, 1978. To extend the closing date one month, a written request must be filed with the Editor of Technical Publications, ASCE. This paper is part of the copyrighted Journal of the Hydraulics Division, Proceedings of the American Society of Civil Engineers, Vol. 104, No. HY4, April, 1978. Manuscript was submitted for review for possible publication on September 22, 1976.

'Research Engr., Institut für Hydromechanik, Universität Karlsruhe, Karlsruhe, Germany.

${ }^{2}$ Prof., Institut für Hydromechanik, Universität Karlsruhe, Karlsruhe, Germany. 
Dimensional Analysis for Two-Dimensional Sharp-Crested Weirs with Deep Plunge Pools

In air-entrainment problems, the fluid properties of the air can be neglected relative to those of the water (12). Thus for a two-dimensional sharp-crested aerated weir as shown in the definition sketch (Fig. 1), the amount of entrained air per unit width, $q_{a}$, will be a function of water discharge per unit width $q_{w}$, height of fall $h$, gravitational acceleration $g$, and water density $\rho_{w}$, dynamic viscosity $\mu$, and surface tension $\sigma$. With $\left(q_{w}=u D\right)$, in which $u$ and $D$ are the velocity and thickness of the nappe at the surface of the plunge pool, these parameters can be cast into the following dimensionless form:

$$
\frac{q_{u}}{q_{w}}=f\left(\frac{u}{\sqrt{g D}} ; \quad \frac{\rho_{w} u D}{\mu} ; \frac{g \mu^{4}}{\rho_{w} \sigma^{3}}\right)=f(\mathrm{~F} ; \mathrm{R} ; Z)
$$

The "liquid parameter" $Z$ has been considered, among others, by Wegener and Parlange (17) and the second writer (12). It contains only properties of

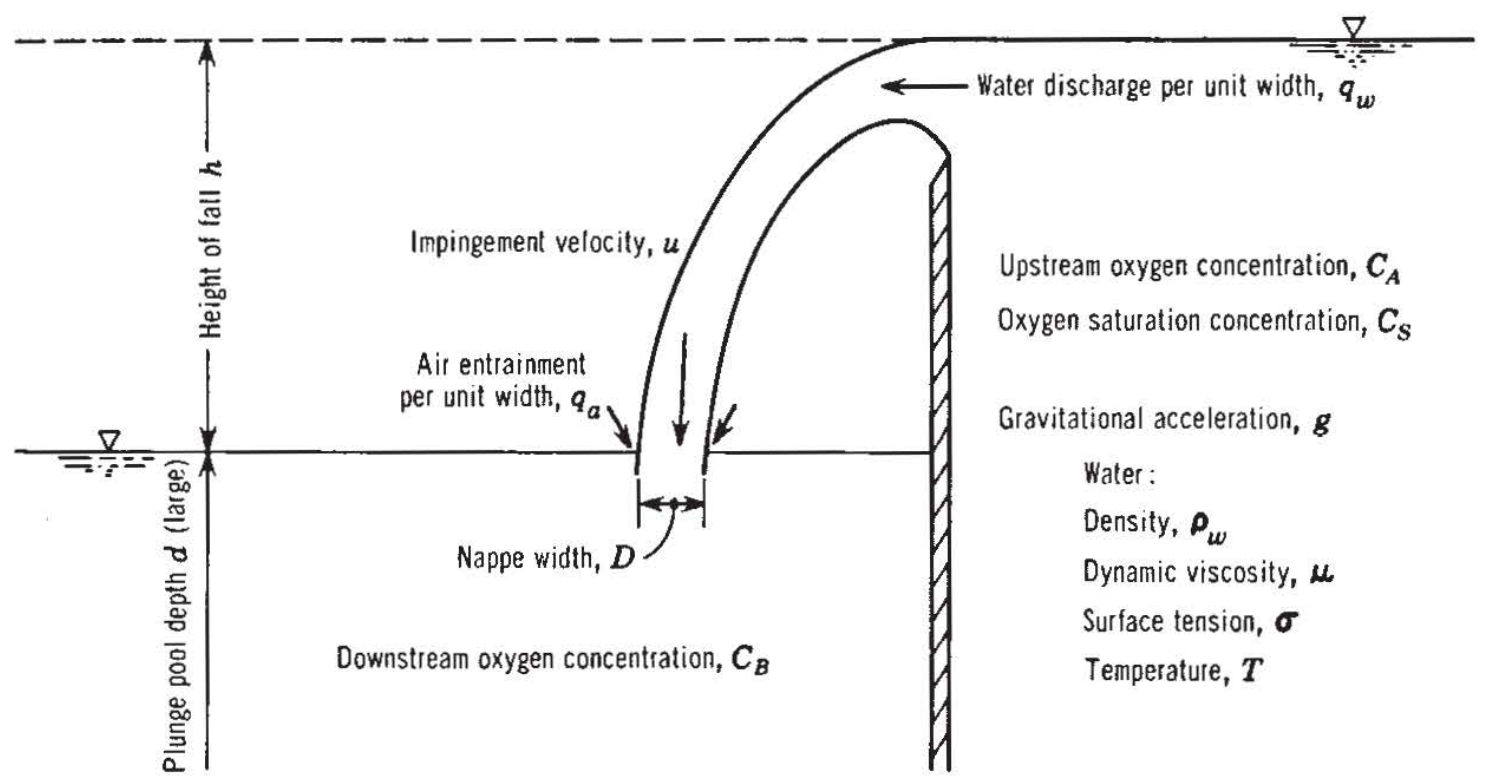

FIG. 1.-Definition Sketch for Two-Dimensional Weir Reoxygenation

the liquid and will therefore be a constant for water of a given temperature and given water quality. For this case the air entrainment will be a function of the Froude $(F)$ and Reynolds $(R)$ numbers only.

Under fully turbulent conditions, as are encountered in large heights of fall and water discharges, the phenomenon becomes dependent on the Froude number only. This can be shown by dimensional arguments. If one assumes that the characteristic velocity responsible for the entrainment of air is the impingement velocity, $u$, of the nappe at the plunge pool surface, given by $\sqrt{2 g h}$, then the air entrainment per unit width, $q_{a}$, will be only dependent on $u, \rho_{w}$, and g. In this case, a dimensional analysis yields only one parameter, which by necessity must have a constant value:

$\frac{q_{a}}{u^{3}}=$ constant or $\frac{q_{a}}{q_{w}}=$ constant $\mathrm{F}^{2}$ 
For the process of reoxygenation, the number of variables increases to include the temperature, $T$, and other relevant water quality parameters. If the reoxygenation rate, $r$, is defined according to the sketch given in Fig. 1 as

$r=\frac{C_{s}-C_{A}}{C_{s}-C_{B}} \geq 1$

then $r$ can be expressed as a function of the following dimensionless variables:

$r=f\left(\frac{q_{a}}{q_{w}} ; \quad T ; \quad\right.$ water quality $)$

with $q_{a} / q_{w}$ given by Eqs. 1 and 2. For water of a given temperature and given water quality, $r$ can be considered to be only a function of the relative air entrainment rate, $q_{a} / q_{w}$.

\section{Nomogram for Weir Reoxygenation}

Following the general form of Eq. 4, and considering the fact that the lower limit of $r$ is equal to one, lines of $(r-1=$ constant $)$ based on the data presented

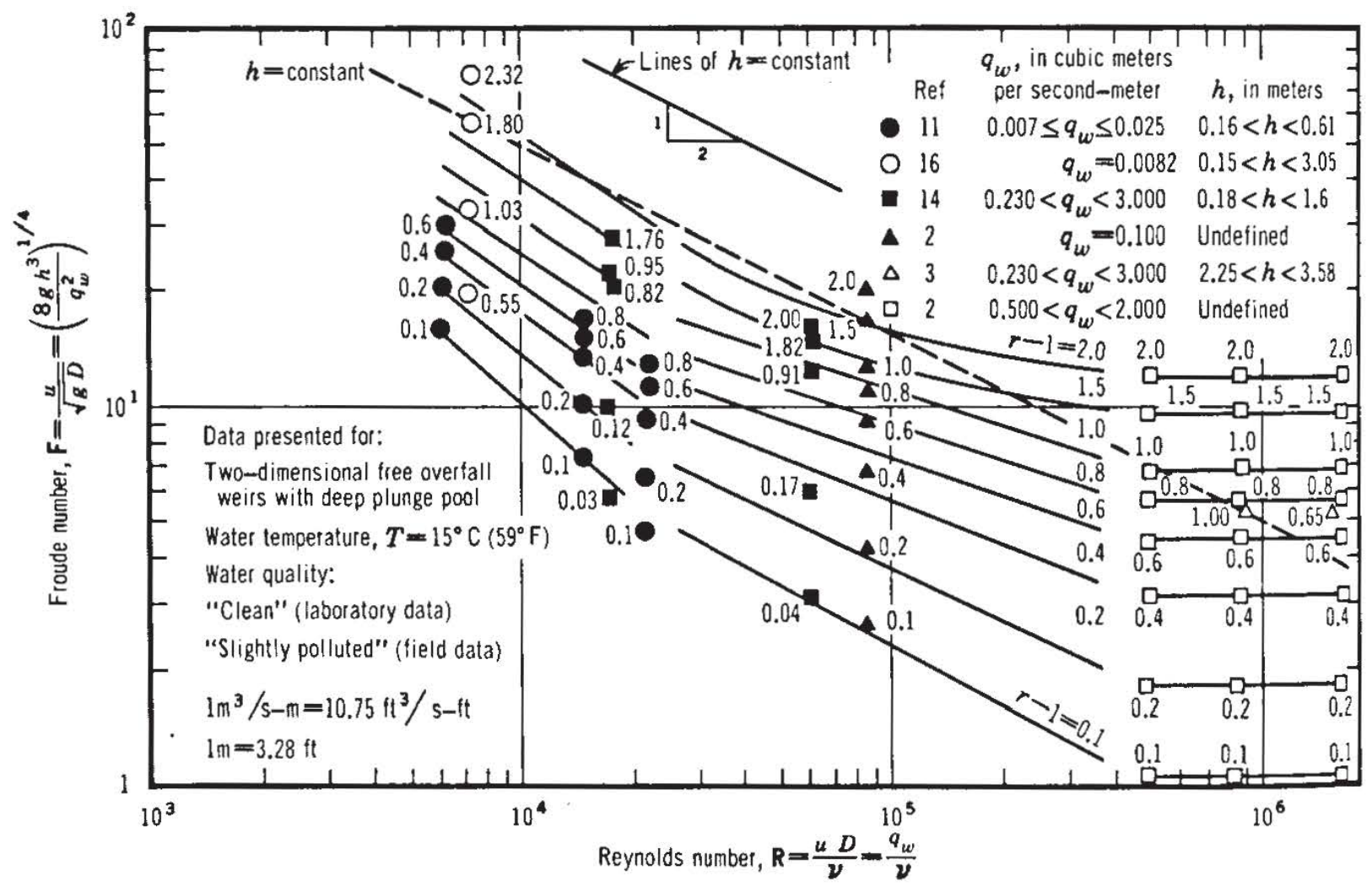

FIG. 2.-Nomogram for Weir Reoxygenation

in Refs. 1, 2, 3, 4, 7, 8, 11, 13, 14, and 16 have been plotted as a nomogram in Fig. 2 on a graph of the Froude versus the Reynolds number. It is noted here that through the substitutions $\left(q_{w}=u D\right)$ and $(u=\sqrt{2 g h})$ the Froude and Reynolds numbers have been transformed into the following forms:

$\mathrm{F}=\frac{u}{\sqrt{g D}}=\left(\frac{8 g h^{3}}{q_{w}^{2}}\right)^{1 / 4} ; \mathrm{R}=\frac{u D}{v}=\frac{q_{w}}{v}$

in which $v=$ the kinematic viscosity of water. 
A brief examination of the trends shown in the nomogram follows.

The nappe Reynolds number for free overfall weirs is directly proportional to the flow rate. Thus, as one proceeds from left to right in Fig. 2, one comes from the laboratory into the field situation, and as one proceeds vertically upward the flow rate remains constant as the height of fall increases. From Fig. 2 it can be seen that, for constant values of flow rate $(R)$, increasing the height of fall $(F)$ increases the reoxygenation rate $r$. In the laboratory and small stream situation $\left(\mathrm{R}<5 \times 10^{5}\right)$, the reoxygenation rate $r$ is dependent on both $\mathrm{F}$ and $R$ while for $R>5 \times 10^{5}$ it depends only on the Froude number and can be approximated by the expression

$r=1+f_{w 4} f_{T}\left(0.1 F^{1.2}\right)$

in which $f_{w q}$ and $f_{T}$ are correction factors for water quality and temperature.

For temperature $T$, in degrees Celsius (from Ref. 6):

$f_{T}=\frac{(r-1)_{T}}{(r-1)_{15^{\circ} \mathrm{C}}}=\frac{1+0.046 T}{1.69}$

for water quality: $f_{w q}=\frac{(r-1) \text { given water quality }}{(r-1) \text { base water quality }}$

$$
f_{w / 41} \text { [laboratory (16)] } f_{w, 2} \text { [field (7)] }
$$

$\begin{array}{lll}\text { clean } & 1.0 & - \\ \text { slightly polluted } & 0.89 & 1.0 \\ \text { moderately polluted } & 0.56 & 0.81 \\ \text { grossly polluted } & 0.36 & 0.69\end{array}$

In general, it can be stated that the measured values of $r$ are within $\pm 25 \%$ of the interpolated values. This reflects the scatter in the laboratory and field data.

Fig. 2 is an attempt to consolidate the work of several authors into a uniform presentation. A diagram of the sort, covering both laboratory and field data, enables a ready evaluation of model-prototype scale effects. However, use of the nomogram for the prediction of weir reoxygenation at a given location should be made with caution. The nomogram was developed using data for weirs with deep plunge pools $(h / d$ is smaller than $3 / 2$, in which $d$ is the plunge pool depth) and for water at $15^{\circ} \mathrm{C}\left(59^{\circ} \mathrm{F}\right)$ of "clean" (laboratory) to "slightly polluted" (field) water quality. According to Ref. 6, weirs with relatively shallow plunge pools or stones on concrete aprons are more efficient for oxygen transfer than deep plunge pools. In addition, the effects of temperature and water quality, further complicated by the unprecise classifications found in the literature, can be quite pronounced. Correction factors $f_{T}$ and $f_{w q}$ can be defined as the ratio of the values of $(r-1)$ determined from the nomogram [i.e., at $15^{\circ} \mathrm{C}\left(59^{\circ} \mathrm{F}\right)$ and at a base water quality] to values at other temperatures and water qualities. The factor $f_{T}$, based on an equation presented in Ref. 16, results in correction for $(r-1)$ of $-41 \%$ for $0^{\circ} \mathrm{C}\left(32^{\circ} \mathrm{F}\right)$ and $+41 \%$ for $30^{\circ} \mathrm{C}\left(86^{\circ} \mathrm{F}\right)$. These 
corrections are based on studies at a constant low flow rate; no other detailed studies are known to the writers from which the effect of the flow rate on the temperature correction factor could be determined.

The correction factors $f_{w q}$ determined from the literature are far from satisfactory due to the broad terminology used. For example, values of $f_{w q}(T=$ constant) based on laboratory studies (16) and field studies (7) are compared. For the present, until more specific data are available, $f_{w q}$ (developed from laboratory data) is assumed to apply to the laboratory situation $\left(\mathrm{R}<10^{5}\right)$ and $f_{w 42}$ (developed from field data) for field situations $\left(R>10^{5}\right)$.

To illustrate the use of the nomogram, the determination of the downstream dissolved oxygen concentration, $C_{B}$, resulting from the flow of $0.5 \mathrm{~m}^{3} / \mathrm{s} \cdot \mathrm{m}$ $(5.37 \mathrm{cu} \mathrm{ft} / \mathrm{sec}-\mathrm{ft})$ over a 1.4-m (4.6-ft) high weir is presented. The water is assumed to be "moderately polluted" at $20^{\circ} \mathrm{C}\left(68^{\circ} \mathrm{F}\right)$ with an initial dissolved oxygen concentration, $C_{A}$, of $2.3 \mathrm{mg} / 1$.

The Reynolds and Froude numbers calculated from Eq. 5 yield values of $\left(R=4.95 \times 10^{5}\right)$ and $(F=5.42)$. With these values, one obtains from Fig. $2,(r-1)_{15^{\circ} \mathrm{C}}=0.76$.

Correcting for temperature and water quality according to the tabulated material previously given (for field situations) yields

$(r-1)_{20^{\circ} \mathrm{c}}=\frac{1+0.046(20)}{1.69}(0.81)(0.76)=0.70 \ldots \ldots$

Therefore, considering the saturation value for oxygen of $\left(C_{s}\right)_{20^{\circ} \mathrm{C}}=8.8 \mathrm{mg} / \mathrm{l}$ and the uncertainity in $r$ of $\pm 25 \%$, Eq. 3 yields

$$
C_{B}=8.8-\frac{6.5}{1.70 \pm 0.42}=4.7 \pm 1.0 \ldots \ldots \ldots \ldots
$$

\section{Scale Effects}

In the laboratory, for low flow rates and low heights of fall (lower left corner of Fig. 2), surface tension prevents air entrainment and therefore reoxygenation from occurring. The effect of surface tension is overcome as a result of an increase in the flow rate or height of fall or both. Air is entrained to greater depths and, with increasing turbulence in the plunge pool, is broken into finer and finer bubbles. Both effects increase the efficiency of the gas transfer process. Thus, in this region reoxygenation increases with both $q_{w}$ and $h$.

In the fully turbulent field situation (right-hand side of Fig. 2), Eq. 2 governs. The amount of air entrainment is determined by the impingement velocity, $u$, at the nappe which is a function of the height of fall $h$ only. Thus, the same quantity of air will be entrained for the same height of fall regardless of the flow rate. Therefore, with increasing water flow rate, there is less air per volume of water available and thus the reoxygenation rate decreases. In the logarithmic parameter presentation of Fig. 2, lines of constant $h$ are given by straight lines with a slope of $-1 / 2$, i.e., parallel to the dashed line. Proceeding along such a line towards higher flow rates, i.e., to the right, shows that for a constant height of fall $r$ decreases with increasing water discharge in the large-scale field situation. On the other hand, $r$ increases with increasing height of fall at a given water flow rate (vertical line). 
In hydraulic models, flow over weirs is usually scaled according to the Froude model law. Two-phase-flow processes, however, are not reproduced to scale in such models. Fig. 2 shows this point. In going from a small scale Froude model to the prototype situation, one proceeds along a horizontal line $(F=$ constant) from left to right (to large $R$ ). From Fig. 2 , it is seen that the reoxygenation rate, $r$, will necessarily be smaller in the model than in the prototype. This is mainly due to the fact that the Froude model does not correctly scale the air entrainment rate, which depends primarily upon the height of fall, $h$. Laboratory experiments for the determination of reoxygenation rates $r$ have therefore of ten been performed at prototype dimensions of $h$. Historically, the results of such studies have been presented in equations in which $r$ is a function of $h$ only $(6,7,8,10,16)$ without consideration of the flow rate, $q_{w}$. Such equations will plot as straight lines with a slope of $-1 / 2$, i.e., parallel to the dashed line in Fig. 2. Therefore, predictions of $r$ from laboratory studies at low flow rates lead to overestimations of $r$ for high flow rates at the same height of fall. This conclusion is consistent with the Environmental Protection Agency finding (6) that the use of an equation for $r$ developed from laboratory data in which $q_{w}$ was not considered yielded "results that were more than a factor of 2 higher than the measured values for the 1.2 and $1.5 \mathrm{~m} \mathrm{(4}$ and $5 \mathrm{ft})$ dams . . .,"

\section{Conclusions}

The literature on reoxygenation studies on free overall weirs has been reviewed with the main objective of investigating model scale effects. A nomogram has been presented for constant values of $(r-1)$ as a function of the nappe Froude and Reynolds numbers. Analysis of the nomogram indicates that small-scale Froude model studies tend to underestimate prototype reoxygenation, whereas laboratory experiments at prototype heights of fall tend to overestimate the reoxygenation if no consideration of flow rate is made. Correction factors for temperature and water quality effects have been examined. It is hoped that this nomogram will serve as a guide to the complicated interrelationships involved in the reoxygenation process and as a method for uniform presentation for comparison of data acquired in the future.

\section{Appendix.-References}

1. Albrecht, D., "Belüftung des Ruhrwassers am Wehr Spillenberg," Die Wasserwirtschaft, Vol. 11, 1968, pp. 317-321.

2. Albrecht, D., "Schätzung der Sauerstoffzufuhr durch Wehre und Kaskaden," Die Wasserwirtschaft, Vol. 11, 1969, pp. 321-323.

3. ATV Arbeitsblatt AW 161, "Die künstliche Belüftung von Oberflächengewässern," ZfGW-Verlag GmbH, Frankfurt, Germany, Jan., 1971.

4. Avery, S., and Novak, P., "Oxygen Uptake in Hydraulic Jump and at Overfalls," International Association for Hydraulics Research XVI Congress, Sao Paulo, Brasil, Vol. III, 1973, pp. 329-337.

5. Barret, G., and Ogden, C. G., "Aeration Studies at Four Weir Systems," Water and Water Engineer, Vol. 64, Sept., 1960, pp. 107-113.

6. Environmental Protection Agency: "Optimal Mechanical Aeration System for Rivers and Ponds," Water Pollution Control Research Series 16080 D007/70, 1970.

7. Gameson, A. L. H., "Weirs and Aeration of Rivers," Journal of the Institute of Water Engineers, London, England, Vol. 11, 1957, pp. 477-490.

8. Gameson, A. L. H., Vandyke, K. G., and Ogden, C. G., "The Effect of Temperature 
on Aeration at Weirs," Water and Water Engineering, Vol. 62, 1958, pp. 489-492.

9. Grindrod, J.: "British Research on Aeration at Weirs," Water and Sewage Works, Vol. 109, Oct., 1962, p. 395.

10. Jarvis, P. I., "A Study in the Mechanics of Aeration at Weirs," thesis presented to the University of Newcastle upon Tyne, England, in 1970, in partial fulfillment of the requirements for the degree of Master of Science.

11. Kayser, R., and Stegmann, R., "Sauerstoffeintrag an Wehren mit geringen Beaufschlagungen," Wasser und Boden, Vol. 2, 1975, pp. 1-24.

12. Kobus, H.: "The Motion of Bubbles in Liquids," Characteristics of Self Aerated Free Surface Flows, N. S. L., Rao, and H., Kobus, ed., Erich Schmidt Verlag, Germany, 1973.

13. Londong, D., "Flußwasserbelüftung an der Lippe," Gewässerschutz-Wasser-Abwasser, Band 1, Aachen, Germany, 1968, pp. 105-119.

14. Londong, D. "Über den Sauerstoffeintrag an freien Überfällen," thesis presented to the Technische Universität, at Aachen, Germany, in 1973, in partial fulfillment of the requirements for the degree of Doctor of Philosophy.

15. Manczak, H., "Verbesserung der Sauerstoffverhältnisse eines Gebirgsbaches mittels Sohlenabstufung," Österreichische Wasserwirtschaft, Vol. 9/10, 1964, pp. 211-216.

16. Water Pollution Research Laboratory, England, "Aeration at Weirs," Notes on Water Pollution, No. 61, June, 1973.

17. Wegener, P. P., and Parlange, J. Y., "Spherical Cap Bubbles," Annual Review of Fluid Mechanics, Vol. 5, 1973, pp. 79-100. 